\title{
THE EDUCATIONAL RESEARCH ON THE WEB - A TWO-EDGED TOOL IN FOCUS
}

Lima, R.M., Oliveira, L.O., Xavier-Filho, J., Oliveira, A.E.A. and Fernandes, K.V.S.

Universidade Estadual do Norte Fluminense, CBB, LQFPP, Campos dos Goytacazes, R.J.

Centro Federal de Educação Tecnológica de Campos, Universidade da Tecnologia e do Trabalho, CEFET/Campos, Campos dos Goytacazes, R.J.

Although the use of the internet is expanding rapidly on college campuses, little is known about student internet use, how students perceive the reality of internet information and how successful they are in searching the internet. The aim of this project is to analyze the biochemical issues available in web pages, evaluating contents quality, trustworthiness and effectiveness. Fourteen sites were analyzed regarding to contents, presence of bibliographical references, authorship, titles responsibility and adequacy to target public. The great majority did not mention bibliographic references and target public. Less than half of the researched sites divulged names and/or graduation status of information providers. Some sites contained critical conceptual errors, such as: participation of $\mathrm{H}_{2} \mathrm{O}$ in the photosynthesis dark phase, carnivore animals feeding only on herbivores, the overall equation of photosynthesis with errors, $\mathrm{NADH}_{2}$ instead $\mathrm{NAD}^{+}$, etc. Half of them presented identical texts and figures. None of the analyzed sites was thus considered excellent. Our data strengthen the need for rigorous evaluation concerning to educational research of biochemical themes on the web.

Supported by: UENF and Cefet/Campos. 